The treatment of psoriasis is therefore mainly or exclusively the treatment of the eruption by external applications. Of these the most active is chrysarobin, in a 6 to $8 \%$ ointment, which, however, should be employed with certain reservations. First, it cannot be used above the neck; secondly, it produces conjunctivitis if it gets into the eyes; thirdly, it stains sheets and clothing permanently; fourthly, it should be used only under careful and continued supervision, preferably keeping the patient in bed. Tar and mercury are also frequently employed, as in Adamson's formula: ammoniated mercury $10 \mathrm{gr}$, liquor picis carbonis 1 drachm, and vaseline to the ounce. Or oil of cade 1 to 2 drachms in salicylic acid ointment one ounce. Success depends upon the vigorous and thorough application of the remedy. Ultra-violet irradiation clears up the eruption in many cases, the patient appreciating the freedom from grease and the shifting of the responsibility for treatment to another. Small doses of $x$ rays are also used in suitable cases-for example, an eruption limited to the elbow. But the cumulative effect of this form of treatment must always be kept in mind, and it should therefore never be used except under expert supervision and by a practitioner fully versed in superficial radiotherapy.

\section{Enlarged Prostate}

Q.-Is there evidence that methyl testosterone is of value in the treatment of early prostatic enlargement? Is such treatment worth while, bearing in mind the possible carcinogenic factor of the hormone, and, if so, over what period should dosage be continued?

A.-There is a good deal of experimental evidence that benign hypertrophy of the prostate is of endocrine origin. There is some clinical evidence that the administration of androgens may arrest further development of hypertrophy of the middle lobe, but on the whole the treatment of the enlarged prostate with androgens has been disappointing. At any rate it would seem that the first essential of such treatment is adequate dosage, and it is doubtful whether this would be obtained with the doses of methyl testosterone by mouth which are now popularly employed. The usual procedure, if androgen therapy is decided upon, is to give injections of, say, testosterone propionate 25 to $50 \mathrm{mg}$. (or even more) weekly for 3 or 4 months, and if no relief is obtained to consider the possibilities of surgery. The cancer bogy has been raised frequently in the course of discussions on oestrogen therapy. So far as is known androgen has up to the present not been accused of being a possible precancerous agent.

\section{INCOME TAX}

\section{Income from New Zealand}

"F.R.C.S." raises two points in connexion with this income: (a) the inspector of taxes suggests that he should drop his claim to Dominion income tax relief, if only the net amount of the income (i.e., after deducting New Zealand income tax) is assessed to British tax; and $(b)$ whether he is liable to account for tax on that portion of the income which accrues in New Zealand but cannot be remitted to this country owing to Government restrictions.

** (a) We distrust these short cuts. The result for the year in question might not differ much-that depends on various facts; but the only safe : ay is to claim what the law gives-i.e., the Dominion income tax r.iief. (b) $\mathrm{He}$ is liable in law, but if payment of tax on the unremitted portion of the income would impose hardship -as it very well may do-we understand that collection of that tax can be held over to be dealt with as and when the income withheld is in fact remitted.

\section{Expense of Travelling to London}

"A. H." inquires whether expenses incurred in travelling to London for (a) meetings of the Royal Society of Medicine and (b) attending hospitals for postgraduate instruction are allowable.

** No; it would, we believe, be held that such expenses are not incurred in the carrying on of professional work, but in raising the standard of professional ability and knowledge.

\section{Deduction for General Expenses}

"SIGMA" has a small specialized practice for which he uses a consulting-room (exclusively) and the dining-room as a waitingroom. The maid acts as receptionist and attends to the telephone. (He is also part-time assistant in another practice, but this does not affect the question raised.) The house is assessed at $£ 70$ per annum. What would be a reasonable allowance from the profits of the practice?

* So far as the rent, rates, etc., of the premises are concerned, we would suggest, say, $20 \%$ as a fair charge. The proportion of the maid's time is difficult to deal with as it depends on the amount of work she has in connexion with the private practice. "Sigma" can probably make an estimate as to the proportion of her time spent on that work. No allowance is due in respect of the part-time assistant work unless the principal requires "Sigma" to maintain a consulting-room for the purposes of his (the principal's) practice.

\section{LETTERS, NOTES, ETC.}

\section{Atmospheric Pollution with Cement Dust}

Mr. P. G. BowIe (Cement and Concrete Association) writes: My attention has been drawn to Mr. D. W. Standley's letter (Nov. 13 , p. 622), and while I appreciate his point that too close an association between housing and industry may not-on account of noise, atmospheric pollution, or for other reasons-be desirable, I would ask that any statement concerning cement manufacture which is published in a journal of such high standing as your own should be based on fact. Cement is not powdered until after it has lefi the kilns, consequently cement dust does not pour out of the chimneys. What is often visible is the cloud of steam evaporated from the wet clay from which the cement is made. Flint dust is not used in the manufacture of cement, and you may be certain that having gone to the expense and trouble of making and then crushing the cement to powder the manufacturers do all in their power to minimize any loss of material.

\section{Pleuro-pericardial Rub}

Dr. W. Trevor CoOKe (Birmingham) writes: The signs and symptoms given in the question "pleuro-pericardial rub" (Oct. 23 p. 533) are very similar to those described by Hamman (Johns Hopk Hosp. Bull., 1939, 54, 1). He called attention to the significance of previously recorded cases, and reported 7 cases under the term of "spontaneous mediastinal emphysema." The condition is benigri and is frequently confused with coronary thrombosis owing to the intense pain and collapse that may be present, and with pericarditic due to the auscultatory findings. Six of Hamman's cases were under the age of 35 . In view of the ease with which the diagnosis mas be confused with more serious conditions, spontaneous mediastina emphysema should be more widely recognized, and the possibility of its occurrence should be considered in the case discussed in the question.

\section{Wilson's Disease}

Dr. A. J. Glazebrook writes from Edinburgh: The question of a family history of encephalitis lethargica is discussed in the Journal of Nov. 13 (p. 631). In a few cases of Wilson's disease that I have seen the condition has usually been misdiagnosed as encephal itis lethargica. This rare condition is familial. One of the cases I have seen was clearly hereditary. The fact that "the girl has an attitude and a way of speaking which are a trifle lethargic," and the family history, suggest to me that Wilson's disease should be excluded before child-bearing can be safely advised. I am interested in hepato-lenticular degeneration and would be grateful for further details of the case.

\section{Subungual Haematoma}

Dr. J. Barr Stevens (London, N.4) writes: The easiest way to treat this condition is as follows. Having cleaned the toe or finge as much as possible, run a tenotomy or other straight knife down to the base of the nail, above the nail but below the cuticle, and turn it sideways with the cutting edge down. Blood will immediately escape by the side of the knife and give relief. The procedure can be done so quickly as to be practically painless, and is quicker and easier than attempting to perforate the nail with knife or drill.

\section{Leicester Christian Medical Association}

Dr. E. K. MACDONALD, medical officer of health, Leicester, writes: I have been instructed, as honorary secretary to the above association, to advise you of its formation. Some little while ago a meeting was held of medical practitioners in this area who felt that it was most desirable that the influence of Christianity should be borne in mind in our practice of our profession, and it was decided to form an association with the object of promoting the profession and practice of Christianity among the medical men and women resident in the city of Leicester and counties of Leicestershire and Rutland. Any medical man or woman in the area who accepts the Christian Faith is eligible for membership. Honorary members have been invited, and have accepted our invitation, from the three main Christian denominations-viz., the Lord Bishop of Leicester, the Very Reverend Father Prior (Roman Catholic), and the President of the Free Church Council. In addition, two associate members from each of the three denominations have been appointed from among the clergy. Up to the present we have some forty members, and our first meeting, which was held recently, was addressed by the Bishop of Leicester, who dealt with the question of co-operation between the clerical and medical professions. An interesting programme of meetings has been arranged during the winter. The chairman of the association is Dr. J. V. C. Braithwaite and the council is representative of all denominations.

\section{Corrigendum}

Mr. G. F. LANGLEY wishes to correct a serious error in his article on gunshot wound of the innominate artery published on Dec. 4 (p. 711). In lines 13 and 14 of the clinical history the sentence should read: "There was a round wound half an inch in diameter just above the midpoint of the right clavicle." 